\title{
BMJ Open The UK Freedom of Information Act (2000) in healthcare research: a systematic review
}

\author{
Alexander J Fowler, ${ }^{1}$ Riaz A Agha,${ }^{2}$ Christian F Camm, ${ }^{3}$ Peter Littlejohns ${ }^{4}$
}

To cite: Fowler AJ, Agha RA, Camm CF, et al. The UK Freedom of Information Act (2000) in healthcare research: a systematic review. BMJ Open 2013;3:e002967. doi:10.1136/bmjopen-2013002967

- Prepublication history for this paper is available online. To view these files please visit the journal online (http://dx.doi.org/10.1136/ bmjopen-2013-002967).

Received 28 March 2013 Revised 11 October 2013 Accepted 15 October 2013

CrossMark

\begin{abstract}
${ }^{1}$ Barts and the London School of Medicine and Dentistry, QMUL, London, UK ${ }^{2}$ Department of Plastic Surgery, Stoke Mandeville Hospital, Aylesbury, Buckinghamshire, UK ${ }^{3}$ New College, University of Oxford, Oxford, UK ${ }^{4}$ Department of Primary Care and Public Health, Kings College London, London, UK
\end{abstract}

Correspondence to Alexander J Fower; ha09410@qmul.ac.uk

\section{ABSTRACT}

Objectives: To assess the use and utility of the Freedom of Information Act (2000) in healthcare research since 2005 and to determine if any particular feature of studies found led to greater data acquisition.

Design: PRISMA compliant systematic review.

Participants: An extensive literature search was performed of EMBASE, MEDLINE, CINAHL, psychINFO, BNI, AMED, HMIC and Health business elite databases from January 2005 to January 2013 using terms 'Freedom of information', 'Freedom of information act' and 'Freedom of information act 2000'. Papers were considered for publication if they described utilising the UK Freedom of information act to gather data for healthcare research. 16 articles met these criteria.

\section{Primary and Secondary outcome measures:}

Primary outcome was the number and characteristics of studies utilising the Freedom of Information Act to collect the data for healthcare research. Secondary outcome measures were any features that improved data acquisition rates (including to whom the request was made, the number of questions asked per request, etc.)

Results: 16 articles described utilising the Freedom of Information Act for healthcare research, and these investigated a broad range of topics. The median number of requests made was 86 (range 1-172), the total number of requests was 1732. A total of 15817 pieces of data were retrieved by all studies. The amount of data collected was defined as the number of questions asked multiplied by the number of full responses. A median of five questions were asked per study (range 5-6.5) and the overall response rate was $86 \%$. The National Health Service litigation authority responded to $100 \%$ of requests, while Primary Care Trusts had the lowest response rate of $81 \%$ for healthcare bodies. A positive correlation between number of requests made and data obtained $(0.508$, $p<0.05)$ and number of requests made and increased response rate $(0.737, p<0.01)$, both reached the statistical significance.

Conclusions: Researchers should make greater use of the Act to access the information they need that is not otherwise disclosed. We discuss the issues with the research utilising the Act and how future research of this type could be optimised.

\section{Strengths and limitations of this study}

- Systematic review; adhering to the Preferred Reporting Items for Systematic Reviews and Meta-Analyses guideline and a thorough literature search.

- Lack of studies currently using the Freedom of Information Act and there is an element of publication bias within the available literature, as those that had minimal findings are unlikely to achieve publication.

- Difficulty in determining whether or not studies utilised the Freedom of information act and the amount of data obtained by those studies.

\section{INTRODUCTION}

The UK Freedom of Information Act (FOI) passed into law in 2000, coming into full force in 2005. ${ }^{1}$ This made provision for "the disclosure of information held by public authorities or by persons providing services for them". ${ }^{1}$ Under the Act, a request for disclosure of information can be made to any number of public bodies. There are over 100000 organisations which include education authorities, local government, publically owned companies and the National Health Service (NHS). ${ }^{1}$

A written communication asking for release of information is all that is needed; no reference to the FOI act itself and no explanation of why the information is being sought are required. ${ }^{1}$ When an FOI request is made, the body being requested must state whether or not it holds the information being requested and must disclose that information, unless the data are exempt, within 20 working days. ${ }^{1}$ The Act itself is implemented and maintained by the office of the Information Commissioner, who has the power to force the disclosure of information when a request is being unfairly rejected. ${ }^{2}$

Use of the FOI Act potentially provides access to a significant amount of information for a variety of research purposes. In 
particular, research into healthcare systems, where data obtained from multiple NHS trusts can provide a rich corpora of data swiftly. The FOI Act has been used extensively by the mass media, requesting large sets of information, not only from the NHS but also from many other parts of the government. ${ }^{3}$ In 2006, private individuals made the majority of requests $(60 \%)$, journalists made $20 \%$, and the remaining $20 \%$ was made up by businesses and other groups. ${ }^{3}$ In this systematic review, we investigate the use and utility of the FOI Act in healthcare research since its implementation in 2005 and discuss its possible uses in the future.

\section{METHODS}

\section{Search method}

An online search of the EMBASE, MEDLINE, CINAHL, psycINFO, BNI, AMED, HMIC and Health business elite databases was conducted from January 2005 to January 2013 using the terms 'Freedom of information', 'Freedom of information act' and 'Freedom of information act 2000'. A manual search through the references of articles located by the search strategy and meeting inclusion criteria was also performed. The search was restricted to the English language papers only. Abstract results were manually searched by one of the authors (AJF) to exclude duplicates and those studies not utilising the FOI Act specifically to obtain information related to healthcare. Studies were included if they described utilisation of the FOI Act to obtain data. Papers were excluded if they lacked formal research methodology, if they reported findings made by another group's FOI request or if the data obtained by the FOI Act request was not specified (ie, if they used FOI to fill the gaps in the datasets and did not report on the outcome of these requests).

\section{Data extraction}

Data were extracted from articles once they were deemed to be suitable for inclusion by two authors (AJF and CFC). Data extracted were divided into two major groups, background information regarding the paper and factors that may be related to improved response and data acquisition rates. Background data included the place of publication, year of publication, year in which the FOI Act request was made, the number of requests made and to whom the request was made. The specific factors that were believed to be related to improved response and data acquisition rates included: the number of questions posed per request, how many years worth of data was requested, the response rate, the amount of data collected and the specific area of the research.

\section{Statistical methods}

All data were compiled using Microsoft Excel 2007 (Microsoft, Redmond, Washington, USA) and descriptive statistics were obtained using this software. Spearman's $r$ was used to establish the association between the number of questions asked, response rate, amount of data received and the number of requests sent. This analysis was performed using SPSS V.21 (IBM Corporation, New York, USA); two-tailed Spearman's $r$ test was used and the association was considered significant if $\mathrm{p}<0.05$.

\section{RESULTS}

The initial literature search retrieved 122 records. One additional paper was identified from manual search. After screening and eligibility stages 16 records remained and were included in the analysis (see PRISMA flow chart in figure 1$)^{4}$

Across the 16 papers included in the analysis 1732 requests were made. The median requests made were 86 per paper (range 1-172). A median of five questions were asked (range 4-6.5) per request. A number of different subject areas were investigated. The median number of years data requested for was 3 (range 2-6), and these years ranged from 1995 to 2012.

There was a significant correlation between the number of requests made and the number of data obtained (Spearman's $\mathrm{r}$ 0.508, $\mathrm{p}<0.05$ ), and as the number of requests increased, so did the response rate (Spearman's $\mathrm{r}$ 0.737, $\mathrm{p}<0.01$ ). This correlation calculation was carried out utilising all included studies $(n=16)$.

There were 1480 responses that included the full data requested (provided the data were available) for 1732 requests made, representing a response rate of $86 \%$. Response rate was calculated as the number of full data responses divided by the number of requests made. In total, 15817 pieces of data were retrieved by all studies - a median of 387 pieces of data (range 188-1232). A 'piece' or unit of data was calculated as the number of full responses multiplied by the number of questions asked in the initial request. In the case of the NHS Litigation Authority (NHSLA), it was the number of cases disclosed, as the involved studies only requested this data from them. Data collected for a number of distinct annual periods were multiplied by the number of such periods. The total pieces of data therefore represents the number of fully answered questions. Table 1 is a summary of included studies. Table 2 summarises to whom requests were made, the number of requests made, number of responses with full data, the calculated response rate and the actual amount of data obtained. Three articles $(18.8 \%, 3 / 16)$ noted the average response time, and one left an arbitrary cut-off of 52 days. The average response time was 29 days in the three studies reporting it (table 2).

Requests have grown each year since 2007, after an initial surge in 2005 and numbered over 45000 in 2011 to centrally monitored bodies-not including specific NHS trusts or any outside agencies providing services privately. ${ }^{21}$ Centrally monitored bodies are a large part of the central government that have their FOI activity and responses frequently monitored, for example, the 
Figure 1 Preferred reporting items for systematic reviews and meta-analyses flow chart of paper selection for this systematic review.

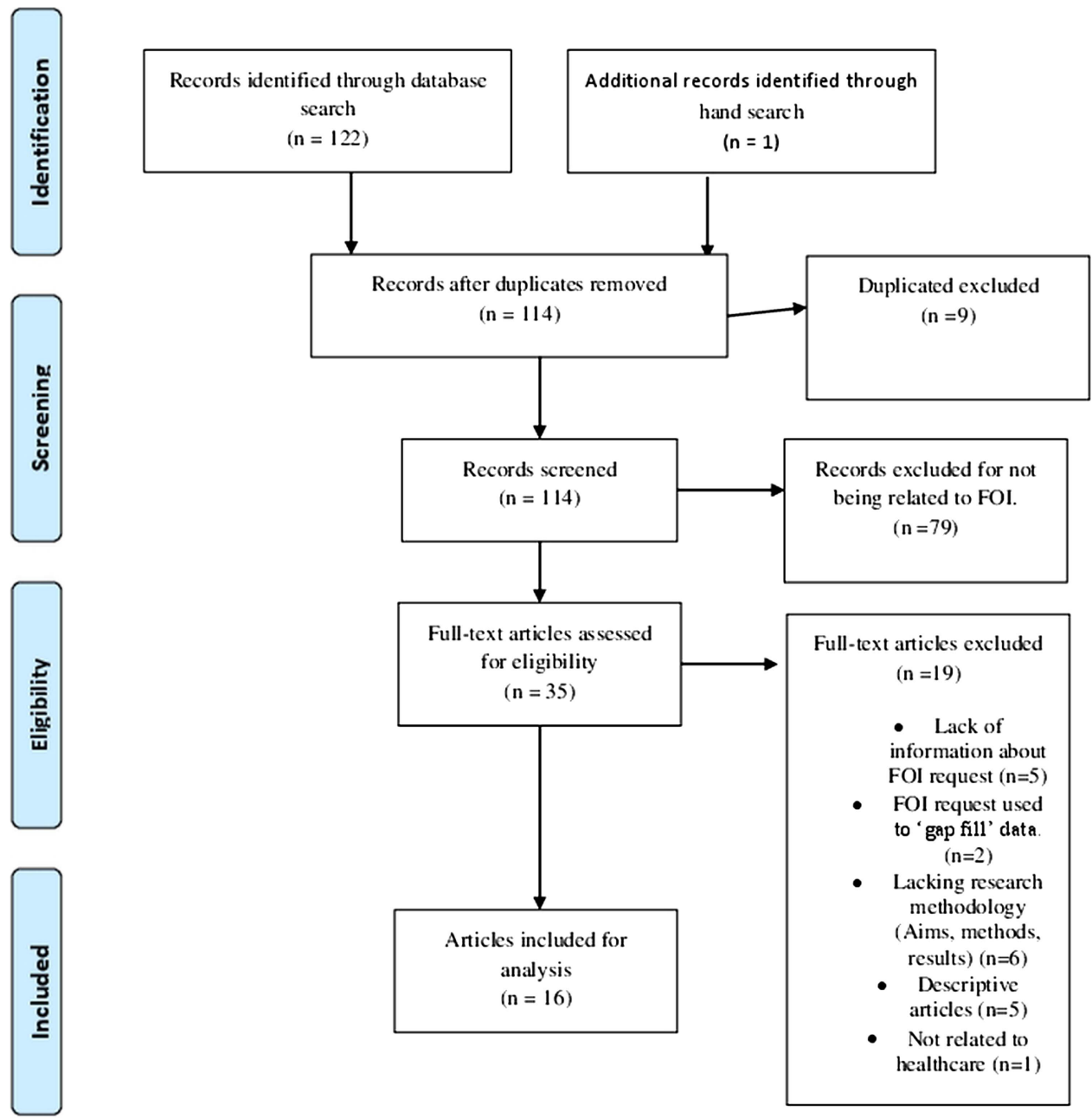

Department of Health. Table 3 shows the number of requests made to centrally monitored bodies each year.

\section{DISCUSSION}

Across the 16 studies judged to be eligible, the majority of data was obtained from $(30 \%, 4934 / 15817)$ and most requests $(44 \%, 757 / 1732)$ were made to Primary Care Trusts (PCT). A total of 15817 pieces of data were retrieved by the combined studies and they covered areas as diverse as litigation, surgical provision and surveillance, costs and funding of rarer cancer, laboratory provision, pharmacological safety and midwifery discipline. The median number of pieces of data received per study was 387, a relatively large dataset, especially given the ease of access to it. The response rate was $86 \%$ (1480/1732) for all included studies. This is comparatively favourable than other methods of data collection. ${ }^{23} 24$

Three studies reported the reasons why they felt data were not obtained, but none provided actual reasons. ${ }^{9} 1718$ One study reported the cost and commercial interests as being barriers to full information disclosure. $^{18}$ One other study felt there were difficulties in interpreting the request by the bodies. ${ }^{9}$ Finally, two studies felt that trusts were unable to compile the data due to unavailability of information. ${ }^{17} 18$ The average response time of 29 days is longer than the 20 working days outlined in the Act but only three articles reported response time and did not clarify if they were working days. ${ }^{1}$

The positive correlation between the number of data obtained and the number of requests made is to be expected. Obviously, as the number of sources from which data are requested increases, the number of data obtained from such requests should increase. The improvement in response rate as more requests are made indicates that the large majority of providers respond well and the effect of those that do not is reduced. As such, more data may be obtained by maximising the number of requests made, as may the response rate.

No other feature was significantly associated with obtaining more information, but the lack of a significantly negative correlation between the number of questions asked and the response rate indicates that there is no optimal number of questions. This was examined to see if higher numbers of questions led to a reduced response rate. It is possible that by asking too many 
Table 1 Summary of included papers

\begin{tabular}{|c|c|c|c|c|c|c|}
\hline Author & Year & $\begin{array}{l}\text { Number of } \\
\text { requests made }\end{array}$ & $\begin{array}{l}\text { Number of } \\
\text { questions/ } \\
\text { request* }^{*}\end{array}$ & $\begin{array}{l}\text { Years of data } \\
\text { requested }\end{array}$ & $\begin{array}{l}\text { Number } \\
\text { of full data } \\
\text { responses }\end{array}$ & $\begin{array}{l}\text { Number of } \\
\text { data† }\end{array}$ \\
\hline Grewal et af & 2013 & 179 & 7 & 2012 & 175 & 1225 \\
\hline Matthew et a $\rho$ & 2013 & 1 & 1 & 1995-2009 & 1 & 1253 \\
\hline Gulati et al & 2012 & 1 & 1 & 1995-2010 & 1 & 318 \\
\hline Milligan et $a \beta^{\beta}$ & 2011 & 1 & 1 & 2005-2009 & 1 & 768 \\
\hline $\operatorname{Gan}^{9}$ & 2012 & 299 & 5 & $\begin{array}{l}2008 / 2009,2009 / \\
2010,2010 / 2011\end{array}$ & 247 & 3705 \\
\hline $\begin{array}{l}\text { The Royal College of } \\
\text { Surgeons of England }\end{array}$ & 2010 & 164 & 3 & 2007-2009 & 96 & 288 \\
\hline Raine $^{11}$ & 2011 & 1 & 1 & 2005-2010 & 1 & 195 \\
\hline Buhanan et $a l^{12}$ & 2012 & 1 & 1 & 1995-2008 & 1 & 126 \\
\hline Kalejaiye and Pear ${ }^{13}$ & 2012 & 129 & 3 & NOT DOCUMENTED & 122 & 366 \\
\hline Chaudhari and Kilby ${ }^{14}$ & 2011 & 161 & 4 & $2007-2010$ & 102 & 408 \\
\hline Goldenberg and French ${ }^{15}$ & 2011 & 170 & 5 & 2008-2009 & 167 & 1670 \\
\hline Rigbye and Griffiths ${ }^{16}$ & 2011 & 327 & 13 & 2008-2009 & 327 & 4251 \\
\hline Aujla et $a l^{17}$ & 2011 & 195 & 5 & 2005-2008 & 150 & 750 \\
\hline Payne-James et al ${ }^{18}$ & 2009 & 43 & 4 & 2000-2008 & 41 & 164 \\
\hline Agha $^{19}$ & 2012 & 36 & 6 & 2005-2009 & 27 & 162 \\
\hline $\begin{array}{l}\text { The Royal College of } \\
\text { Midwives }\end{array}$ & 2012 & 24 & 8 & 2010-2011 & 21 & 168 \\
\hline Total & - & 1732 & - & - & 1480 & 15817 \\
\hline
\end{tabular}

questions, the cost limit of $£ 600$ outlined in the Act might be reached and therefore data not obtained. We cannot comment on the optimal number of questions or of requests. To encourage data collection, it seems sensible that questions should be carefully considered, stated clearly and simply. Before a request is made, a thorough search of the existing national databases and the public bodies own website should be made to determine if such information is already in the public domain.

Questions were being asked across a cross-section of NHS, indicating that these studies are investigating the wider scope of NHS. Previously, obtaining such information apart from official reports and documents was challenging. One of the included articles attempted to obtain data by a simple letter, and achieved a response rate of $11 \%$; this improved to $83 \%$ after making the FOI Act request. ${ }^{19}$ A similar act passed in the USA in 1966 led to a vast public health and medical research output. ${ }^{25}$ The FOI Act in the UK now enables researchers to access a similarly large amounts of data pertaining to the entirety of the health service at minimal expense-both financially and with respect to time for researchers.

While the use of FOI may be financially beneficial for those performing research, questions have been raised

Table 2 Showing bodies, the requests made to them, their full data responses, response rate and actual number of data received by authors

\begin{tabular}{lccrr} 
Body & $\begin{array}{l}\text { Requests } \\
\text { made }\end{array}$ & $\begin{array}{l}\text { Responses } \\
\text { with full data }\end{array}$ & $\begin{array}{l}\text { Response } \\
\text { rate (\%) }\end{array}$ & $\begin{array}{l}\text { Data } \\
\text { received }\end{array}$ \\
\hline Primary Care Trusts & 757 & 615 & 81 & 4934 \\
Acute Care Trusts & 636 & 541 & 85 & 4402 \\
Foundation Trusts & 213 & 203 & 95 & 2811 \\
Mental Health Trusts & 58 & 58 & 90 & 754 \\
Constabularies & 43 & 41 & 85 & 164 \\
Strategic Health Authorities & 20 & 4 & 100 & 182 \\
NHS Litigation Authority & 4 & 1 & 86 & 768 \\
National Reporting and Learning Service & 1 & 1480 & & 15817 \\
Total: & 1732 & & &
\end{tabular}


Table 3 The number of requests made to centrally monitored bodies since $2005^{522}$ *

\begin{tabular}{ll}
\hline Year & $\begin{array}{l}\text { Number of requests to } \\
\text { centrally monitored bodies }\end{array}$ \\
\hline 2005 & 38108 \\
2006 & 33668 \\
2007 & 32978 \\
2008 & 34950 \\
2009 & 40548 \\
2010 & 43921 \\
2011 & 47141 \\
2012 & $37313^{*}$ \\
\hline${ }^{2} 2012$ Includes the first three-quarters of 2012.
\end{tabular}

about the collective cost of the FOI Act. ${ }^{26}{ }^{27}$ Cost is one of the exemptions made in the Act, where a request must cost under $£ 600$ to respond to. ${ }^{1}$ If requests are made to multiple trusts then the cost of the research to the NHS would be larger, rather than relying on the funding received by researchers. ${ }^{14} \mathrm{~A}$ report compiled investigating the financial impact of the FOI Act estimated that over £24 million was spent by the central government on FOI requests in 2006. ${ }^{3}$ Requests going to those outside of central government (including Social Health Authorities) were estimated to cost $£ 8$ million. Such estimations are limited due to the variable local costs in response to requests. ${ }^{3}$ If every request included in this analysis cost half the recommended amount of $£ 600$, then the total cost to the NHS of such research would be over $£ 450000$.

There have been many criticisms of the FOI Act. These include the ease of 'fact fishing' where huge amounts of data can be obtained and trawled for any discrepancy. ${ }^{28}$ As with any retrospective analysis, proper methodology with a hypothesis formed before obtaining data should help allay such concerns for medical literature. Indeed, such data mining may lead to serendipitous results. There have been many prominent critics, including many members of the government that introduced the initial white paper. ${ }^{29}$ Former Prime Minister Tony Blair himself described it as a 'dangerous act', and while he felt it would empower people by shining 'light' on the government and making them more accountable, it has had some unintended consequences, such as the extensive use by the media to investigate all aspects of the government. ${ }^{30}$

A report by a former senior civil servant into the FOI Act found that it had improved transparency and accountability, but had reduced trust and participation in government. ${ }^{31}$ The importance of government being able to debate in confidence, to allow civil servants to give frank analysis and the negative reporting employed by the mass media were other key issues that the former Prime Minister raises in his memoirs. ${ }^{17}$

In the era of open access research and preregistration of trial information and protocols on publically accessible databases, having raw data available openly is a key aspect of academic freedom. ${ }^{32}$ In an increasingly connected world, data being easily available allows timely dissemination of important advances and findings. Having data available for scrutiny is a key part of the scientific method, just as having a protocol and ethics are. Data should be made available for independent assessment and analysis; the $B M J$ has made this a requirement for clinical trials of drugs and devices as of $2013 .^{33}$

With a universal ease of access to data comes the issues surrounding research ethics and access to data obtained by research. The most prominent example of this was a request made by a major tobacco conglomerate in 2011. They requested data from a group at the University of Stirling who were investigating the opinion of teenagers about plain packing. ${ }^{34} 35$ Academics argued that releasing such information could jeopardise future work if young people were thinking that their opinions were being used to form the tobacco industry's marketing campaigns. If forced to disclose, as they eventually were, they argued it would have vast implications on academic freedom. ${ }^{22}$

One prominent criticism of the FOI Act is the provision for ministerial veto. ${ }^{36}$ This came to light with regard to a request for access to the NHS 'risk register'. A document was prepared outlining the potential damage caused by NHS restructuring under the white paper of 2010. ${ }^{37}$ This led to the questions surrounding what data and predictions were contained within the document and worries related to the NHS changes. ${ }^{38}$ This is perhaps the most worrying aspect of the FOI Act for healthcare researchers. That is the highly politicised nature of the NHS and the potential political problems of such a document's release. Data that might be useful to researchers could be held back to prevent such embarrasment. $^{9} 17$

The FOI Act gives access to a plethora of data and the potential of using such data is only as limited as the questions posed by researchers. In this review, the FOI Act was primarily used to investigate the metrics of performance across large portions of the NHS but should not be limited to this. Research utilising the FOI will become especially important for monitoring the impact of changes to the structure and practice of the whole NHS on outcomes following from the reforms of the NHS Bill 2012. ${ }^{24}$ The possibility of utilising the FOI act itself to ask about how many FOI requests had been made for the purposes of research was considered. However, the condition that there is no requirement to state the purposes for requesting information and the broad, heterogeneous bodies from which this information were requested means this would likely have been futile.

Greater transparency itself can help improve outcomes. For instance, Bridgewater $e t a l^{9}$ demonstrated that publication of surgeon-specific mortality data following the Bristol inquiry led to a reduced mortality in cardiac surgery. A greater transparency in a wide range of 
medical specialities may well have a similar impact and FOI could be an important tool facilitating such transparency as part of a wider information revolution. ${ }^{26} 40$

This analysis is limited by the fact that the actual number of studies utilising the UK incarnation of the FOI Act for healthcare research are relatively few and there was inclusion of only English language papers. The lack of studies located limit the analysis of the FOI Act's value as a research tool. The impact of language discrimination is likely to be minimal, given the research pertained to the UK FOI Act. Inclusion of articles utilising the Scottish Freedom of Information Act-as opposed to the UK FOI Act-may have yielded further examples of FOI use. ${ }^{41}$ It is also possible that research that had no findings or found it very difficult to obtain information would not be submitted or accepted for publication and as such there may be a certain level of publication bias. Authors may also not describe their work as utilising the FOI Act for data collection, therefore meaning that research using the Act may not be characterised as doing so. ${ }^{28}$

Whether or not a paper was true research, rather than just making large scale FOI requests and then scouring the data for inconsistencies was hard to distinguish, and was based on whether or not the article outlined it's research methodology. This may have excluded some valid studies, although given their lack of described methodology; such papers would likely have been of poor quality. Another difficulty was in extraction of data; specifically discerning the number of data obtained. For example, one article reported over 800000 data relating to Clostridium difficile infections. However, this was the answer to a question, rather than obtaining 800000 individual data points, so was not included in the number of data obtained. ${ }^{5} 9$ Finally, we had no way of assessing the quality of data collected. While there is a legal requirement to disclose accurate information, the methodology of the initial collection of the data may not be uniform and therefore raises unknown biases within the data set.

To allow greater assessment on how the FOI Act has been used, the patterns of data distribution and to standardise the data collection, a formatted checklist would be beneficial. This would hopefully result in future studies of this kind having equivalent methodology to allow better comparison; and therefore more significant conclusions, to be drawn from the data. This would ideally include:

1. Which body/bodies data were requested from?

2. How many and what questions were asked?

3. The rate and timeframe of responses

4. Reasons given when data were not released

5. Amount of data received

\section{CONCLUSION}

To our knowledge, this is the first systematic review looking into the use of the FOI Act in healthcare research. The FOI Act has led to easy access to a large amount of data across the whole of the NHS, which were previously challenging to access. As changes to this service occur, judicious use of FOI Act requests could lead to careful and accurate monitoring of a variety of measures-be they medical, legal or financial. A greater number of requests improves the overall response; both in terms of data volume and response rate.

Given the vast corpora of data that is available, the lack of published work is perhaps surprising, but we hope that through a greater understanding of what is required to make a request and what kind of data is available by request, this very valuable resource can be maximised in healthcare research.

Acknowledgements The authors would like to thank Lorena Cascant, Clinical Outreach Librarian, Buckinghamshire Healthcare NHS Trust, Wilfred Stokes Library, Stoke Mandeville Hospital, Mandeville Road, Ayelsbury, Bucks HP21 8AL.

Contributors AJF was involved in data acquisition and analysis, drafting the article, critical revision of the article and final approval of the manuscript to be submitted. RAA was involved in concept, literature search, study design, critical revision of the article and final approval of the manuscript for submission. CFC was involved in data extraction and interpretation. PL was involved in the concept, critical revision and final approval of the manuscript for submission.

Funding This research received no specific grant from any funding agency in the public, commercial or not-for-profit sectors.

\section{Competing interests None.}

Provenance and peer review Not commissioned; externally peer reviewed.

Data sharing statement All literature search results held by (AJF).

Open Access This is an Open Access article distributed in accordance with the Creative Commons Attribution Non Commercial (CC BY-NC 3.0) license, which permits others to distribute, remix, adapt, build upon this work noncommercially, and license their derivative works on different terms, provided the original work is properly cited and the use is non-commercial. See: http:// creativecommons.org/licenses/by-nc/3.0/

\section{REFERENCES}

1. Great Britain. Freedom of Information Act. London: The Stationary Office, 2000.

2. Information Commissioners Office. February 2013. http://www.ico. gov.uk/

3. Frontier Economics Limited. Independent review of the impact of the Freedom of information act: a report prepared for the department for constitutional affairs. October 2006. http://webarchive. nationalarchives.gov.uk/\%2B/http:/www.dca.gov.uk/foi/reference/ foi-independent-review.pdf. February 2013.

4. Moher D, Liberati A, Tetzlaff J, et al. Preferred reporting items for systematic reviews and meta-analyses: the PRISMA statement. Int $J$ Surg 2010;8:336-41.

5. Grewal P, Davis M, Hamilton G. Provision of vascular surgery in England in 2012. Eur J Vasc Endovasc Surg 2013;45:65-75.

6. Matthew RG, Ferguson V, Hingorani M. Clinical negligence in ophthalmology: fifteen years of National Health Service litigation authority data. Ophthalmology 2013;120:859-64.

7. Gulati A, Herd MK, Nimako M, et al. Litigation in National Health Service oral and maxillofacial surgery: review of the last 15 years. Br J Oral Maxillofac Surg 2012;50:385-8.

8. Milligan FJ, Krentz AJ, Sinclair AJ. Diabetes medication patient safety incident reports to the National Reporting and Learning Service: the care home setting. Diabet Med 2011;28:1537-40.

9. Gan S. Lost in translation: how much is translation costing the NHS, and how can we both cut costs and improve service provision? 2020Health, 2012. http://2020health.org/2020health/Publication2012/Professional-Development/Translation-Services.html. February 2013. 
10. The Royal College of Surgeons of England. Locum doctor costs in NHS Trusts in England results of a study from the Royal College of Surgeons of England. November 2010. http://www.rcseng.ac.uk/ publications/docs/locum-doctor-costs-in-nhs-trusts-in-england/@@ download/pdffile/RCS\%20Locum\%20doctor\%20costs\%20-\%20NHS \%20Trusts\%20in\%20England\%200ct\%2010\%20report.pdf. August 2013.

11. Raine JE. An analysis of successful litigation claims in children in England. Arch Dis Child 2011;96:838-40.

12. Buchanan I, Weatherby $M$, Weatherby $S$. Can we use medicolegal experience to improve management of patients with subarachnoid haemorrhage? Clin Risk 2012;18:131-4.

13. Kalejaiye OK, Pear RP. Sex: the new healthcare inequality. BJU Int 2012;109:12.

14. Chaudhari SD, Kilby S. Funding by the SHAs for rarer cancers in England: key success factors in the uptake of cancer drugs fund. Value Health 2011;14:464.

15. Goldenberg SD, French GL. Diagnostic testing for Clostridium difficile: a comprehensive survey of laboratories in England. J Hosp Infect 2011;79:4-7.

16. Rigbye J, Griffiths MD. Problem gambling treatment within the British National Health Service. Int J Ment Health Addiction 2011;9:276-81.

17. Aujla RS, Peysakhova E, Gulihar A, et al. Orthopaedic antimicrobial prophylaxis in the United Kingdom. Eur J Orthop Surg Traumatol 2011;21:21-5.

18. Payne-James JJ, Anderson WR, Green PG, et al. Provision of forensic medical services to police custody suites in England and Wales: current practice. J Forensic Leg Med 2009;16:189-95.

19. Agha R. Towards national surgical surveillance in the UK-a pilot study. PLoS ONE 2012;7:e47969.

20. Royal College of Midwives. Freedom of information request: Midwives and disciplinary proceedings in London. November 2012. http://www.rcm.org.uk/EasySiteWeb/GatewayLink.aspx? alld=314009. August 2013.

21. Ministry of Justice. Freedom of information: statistics on implementation in central government archive. 2005-2009. http:// webarchive.nationalarchives.gov.uk/20110322191207/http:/www. justice.gov.uk/publications/freedomofinformationquarterly-archive. htm. March 2013.

22. Ministry of Justice. Freedom of information: statistics on implementation in central government. 2009-2012. http://www. justice.gov.uk/statistics/foi/implementation/implementation-editions. March 2013.

23. Sitzia J, Wood N. Response rate in patient satisfaction research; an analysis of 210 published studies. Int J Qual Health $C$ 1998;10:311-17.
24. Johnson TP, Wislar JS. Response rates and nonresponse errors in surveys. JAMA 2012;307:1805-6.

25. Berger M. The Freedom of Information Act: Implications for Public Health Policy and Practice. Public Health Rep 2011;126:428-32.

26. Breathnach AS, Riley PA, Planche TD. Use of freedom of information act to produce research on the cheap? BMJ 2011;343: d6129.

27. Ministry of Justice. Memorandum to the Justice Select Committee: Post-Legislative assessment of the Freedom of Information Act. London: The Stationary Office, 2000.

28. Lord Falconer of Thoroton. Lord Williams of Mostyn Memorial Lecture. Gray's Inn, London. 2007. http://webarchive. nationalarchives.gov.uk/+/http://www.dca.gov.uk/speeches/2007/ sp070321.htm. February 2013.

29. Straw J. Last man standing: memoirs of a political survivor. London, UK: Macmillan, 2012.

30. Blair T. A journey. London, UK: Hutchinson, 2010.

31. Hazell R, Worthy B, Glover M. Does freedom of information work? The impact of FOI on Whitehall. Basingstoke, UK: Palgrave Macmillan, 2010.

32. Albert KM. Open access: implications for scholarly publishing and medical libraries. J Med Libr Assoc 2006;94:253-62.

33. Godlee F. Clinical trial data for all drugs in current use. BMJ 2012;345:e7304.

34. Gallagher A. Editorial: keeping research ethics under review. Nurs Ethics 2011;18:751.

35. Christie B. Tobacco company makes freedom of information request for university's research. BMJ 2011;343:d5655.

36. Gay O. Freedom of Information and Ministerial Veto. London: Library of the House of Commons, 2013.

37. Department of Health. Equity and excellence: liberating the NHS (White Paper). London: The Stationary Office, 2010

38. BBC. Ministers block release of NHS risk register. British Broadcasting Corporation. 8th May 2012. http://www.bbc.co.uk/ news/health-17989929. February 2013.

39. Bridgewater B, Grayson AD, Brooks N, et al. Has the publication of cardiac surgery outcome data been associated with changes in practice in Northwest England: an analysis of 25,730 patients undergoing CABG surgery under 30 surgeons over eight years. Heart 2007;93:744-8.

40. Keogh BE, Bridgewater B. Toward public disclosure of surgical results: experience of cardiac surgery in the United Kingdom. Thorac Surg Clin 2007;17:403-11.

41. Booth A Innovative Uses of the Freedom of Information Act (2000) for Research. 2009. http://www.rin.ac.uk/system/files/attachments/ Innovative_Uses_of_the_FOIA_for_Research_updated_paper_by_ Andrew_Booth_Apr_2009.doc. August 2013. 